\title{
Pengaruh Intensitas Menonton Film Di Youtube Terhadap Theory-Of-Mind Anak Usia 4-5 Tahun
}

\author{
Devi Rusli ${ }^{1}$, Dian Novita Ariani ${ }^{2}$, Nurmina ${ }^{3}$ \\ 1,3 Jurusan Psikologi, Universitas Negeri Padang, \\ Jl. Prof. Dr. Hamka Air Tawar, Padang, 25171
}

Email : ${ }^{1}$ devirusli@fip.unp.ac.id, ${ }^{2}$ dianofitariani@alumni.ui.ac.id, ${ }^{3}$ nurminadavy.psi@gmail.com

\begin{abstract}
Abstrak
Kemampuan anak memahami pikiran dan perasaan orang lain orang lain (theory of mind) sangat penting bagi perkembangan kognisi sosial. Film cerita anak yang ditonton melalui saluran youtube diprediksi dapat menghubungkan anak dengan situasi mental orang lain. Penelitian ini bertujuan untuk mengetahui pengaruh intensitas menonton film di youtube terhadap theory of mind anak usia 3-5 tahun. Theory of mind diukur menggunakan skala ToM yang dibuat oleh Wellman dan Liu yang telah diadaptasi kedalam bahasa Indonesia oleh Kuntoro, Saraswati, Peterson dan Slaughter (2013). Intensitas menonton film di youtube diukur dengan menggunakan kuesioner/angket. Skala ToM diberikan kepada 215 anak (98 laki-laki, 117 perempuan), usia 4-5 tahun/48-71 bulan $(\mathrm{M}=60.25, \mathrm{SD}=6.482)$, dan kuesioner perilaku menonton film di youtube diisi oleh orangtua dari anak-anak usia 4-5 tahun. Pengambilan sampel dilakukan menggunakan teknik purposive sampling. Uji hipotetsis penelitian menggunakan analisis regresi sederhana. Hasil penelitian menemukan bahwa $\mathrm{R}=0.019$ dengan $\mathrm{R}^{2}=.000, \mathrm{p}>0.05$, artinya perilaku menonton film di youtube tidak berpengaruh secara signifikan terhadap terhadap theory of mind anak usia 4-5 tahun..
\end{abstract}

Kata kunci: Film Anak di Youtube, Theory-of-Mind, Anak Usia 4-5 tahun.

\begin{abstract}
The child's ability to understand other people's minds (theory of mind) is very important for the development of social cognition. It is predicted that children's films watched through the YouTube channel can connect children with other people's mental situations. This study aims to determine the effect of the intensity of watching movies on YouTube on the theory of mind of children aged 3-5 years. Theory of mind is measured using the ToM scale made by Wellman and Liu which has been adapted into Indonesian by Kuntoro, Saraswati, Peterson and Slaughter (2013). The intensity of watching movies on YouTube is measured using a questionnaire. The ToM scale was given to 215 children (98 boys, 117 girls), ages $4-5$ years $/ 48-71$ months $(\mathrm{M}=60.25, \mathrm{SD}=6,482)$, and the behavior of watching movies on YouTube was filled out by parents of the children. ages 4-5 years. Sampling was done using purposive sampling technique. The research hypothesis test used simple regression analysis. The results of the study found that $\mathrm{R}=0.019$ with $\mathrm{R} 2=.000, \mathrm{p}>0.05$, meaning that the behavior of watching movies on YouTube has no significant effect on the theory of mind of children aged 4-5 years.
\end{abstract}

Keywords: Children's Movies on Youtube, Theory-of-Mind, Children aged 4-5 years;

\section{PENDAHULUAN}

Dilansir dari situs kpai.go.id, Komisi Perlindungan Anak Indonesia dalam kurun waktu 9 tahun (2011-2019) telah mencatat jumlah kasus kekerasan terhadap anak mencapai 37.381. Di awal tahun 2020 (Januari-Februari) sudah ada laporan 2.473 kasus perundungan (bullying) pada anak yang terjadi di lingkungan sekolah maupun di media sosial. Pelaku perundungan tersebut pada umumnya dilakukan oleh teman-temannya sendiri. Fenomena ini menunjukkan semakin rendahnya empati (merasakan apa yang dirasakan orang lain) anak terhadap orang lain. Hasil penelitian Caputi, Lecce, Pagnin, dan Banerjee (2012) menemukan bahwa anak yang memahami keadaan mental orang lain (misal keinginan, pikiran, perasaan dan keyakinan) cenderung sensitif terhadap apa yang dipikirkan dan dirasakan oleh orang lain.) 
Kemampuan anak memahami situasi mental orang lain dalam ilmu psikologi perkembangan dikenal dengan istilah theory of mind (Wellman \& Liu, 2004). ). Sebagian ahli mengatakan theory of mind (selanjutnya disingkat ToM) merupakan bakat alami yang dimiliki manusia (Scholl \& Leslie, 2001), namun sebagian ahli yang lainnya mengatakan ToM diperoleh dari hasil sosialisasi seperti pengasuhan, kehadiran saudara kandung dan lain-lain (Foote \& HolmesLonergan, 2003; Slaughter, Peterson, \& Mackintosh, 2007). Akibat pengaruh faktor sosialisasi, perkembangan ToM pada anak berbeda-beda. Menurut para ahli pemahaman tentang situasi mental orang lain diperoleh sejak usia dini, kemampuan ToM mengalami perkembangan yang pesat pada usia 3-5 tahun (Wellman, Cross \& Watson, 2001; Wellman \& Liu, 2004; Shahaeian, Peterson, Slaughter \& Wellman, 2011).

Konsep ToM mengalami perkembangan seiring waktu. Dimulai dari penelitian Wimmer dan Perner (1983) yang mengukur kemampuan ToM pada anak prasekolah menggunakan konsep false beliefs. Konsep ini bertujuan untuk mengetahui pemahaman anak terhadap belief orang lain yang keliru atau tidak sama dengan realita yang sebenarnya. Selanjutnya penelitian Wellman dan Liu (2004) mengukur ToM dengan menggunakan lima konsep yang dikenal dengan skala ToM. Skala ToM digunakan untuk mengetahui pemahaman anak mengenai konsep diverse desire (DD) yaitu pemahaman anak tentang keinginan orang lain yang berbedabeda, konsep diverse belief (DB) yaitu pemahaman anak tentang keyakinan orang lain yang berbeda, konsep knowledge access (KA) yaitu pemahaman anak tentang pengetahuan orang lain berdasarkan informasi yang diketahui oleh orang tersebut, konsep false beliefs (FB) yaitu pemahaman anak tentang keyakinan orang lain yang keliru dan konsep hidden emotion (HE) yaitu pemahaman anak tentang emosi atau perasaan orang lain yang disembunyikan. Kelima konsep ToM dipahami oleh anak-anak secara berurutan atau bertahap yakni, $\mathrm{DD}>\mathrm{DB}>\mathrm{KA}>\mathrm{FB}>\mathrm{HE}$.

Perolehan ToM selain berhubungan dengan kemampuan anak berempati dengan orang lain, juga dapat meningkatkan penerimaan anak dengan teman sebaya (Slaughter, Dennis, \& Pritchard, 2002; Caputi, Lecce, Pagnin, \& Banerjee, 2012). Anak-anak yang memiliki kemampuan ToM juga mengembangkan berbagai skill yang diperlukan dalam sosialisasi antara lain kemampuan berbagi imajinasi dan bergurau dengan teman sebaya, bernegosiasi, berkompromi, bekerjasama dalam bermain, dan mengikuti aturan dalam bermain. Kemampuan ToM juga berhubungan positif dengan perilaku sosial seperti anak suka menolong orang lain (Slaughter, Dennis \& Pritchard, 2002). Menyadari pentingnya peran ToM dalam mengembangkan kemampuan bersosialisasi pada anak oleh karena itu banyak peneliti yang melakukan riset tentang faktor-faktor yang mempengaruhi perolehan ToM.

Pada tahun 2010, Mar, Tackett dan Moore menemukan bahwa kemampuan ToM dipengaruhi oleh sosialisasi dari media naratif (seperti buku cerita dan film) anak usia 4-6 tahun. Media naratif adalah media berbentuk cerita tentang berbagai macam interaksi sosial seperti konflik, salah paham, pengertian, dan penyelesaian (Kinnebrock \& Bilandzic, 2006). Cerita dalam bentuk buku dan film tersebut dapat membuat anak-anak terhubung dengan situasi yang menggambarkan keadaan mental orang lain seperti perasaan, keyakinan, salah paham, pikiran dan pandangan yang berbeda yang dimiliki oleh tokoh-tokoh di dalam cerita.. Saat anak menyaksikan media cerita anak terhubung dengan berbagai situasi mental tokoh-tokoh sehingga media cerita diduga dapat membantu anak memahami keadaan mental orang lain (Guajardo \& Watson, 2002; Rusli, Ariani, Nurmina, \& Rinaldi, 2021).

Berdasarkan hasil penelitian Mar,Tackett dan Moore (2010) disimpulkan bahwa cerita movie yang ditonton melalui CD/DVD terbukti mendukung kemampuan ToM anak. Dalam penelitiannya, Mar, dkk (2010) menggunakan recognition tests, dimana peneliti meminta orangtua memilih judul film yang dikenali dari daftar film, keterpaparan anak pada media film hanya berdasarkan pada pilihan orangtua pada sejumlah judul dalam daftar yang diberikan. 
Namun pengetahuan orangtua mengenai sejumlah judul film anak tidak mampu menggambarkan keterpaparan anak pada media naratif. Menurut Van Mierlo (2008) jumlah waktu yang dihabiskan anak ketika menggunakan suatu media merupakan indikator penting dalam mengukur keterpaparan pada media. Oleh karena itu, pada penelitian ini, peneliti akan melihat pengaruh intensitas (berapa lama) anak menonton film anak-anak yang diakses melalui youtube. Saat ini anak-anak dengan mudah dapat mengakses film-film melalui saluran youtube secara online. Sebelumnya Nathanson, Sharp, Alade, Rasmussen dan Christy (2013) juga telah meneliti pengaruh keterpaparan acara tv terhadap ToM pada anak prasekolah. Hasil penelitian menemukan bahwa anak-anak yang menonton tv disertai diskusi dengan orangtuanya memiliki performa ToM yang lebih baik dibandingkan anak-anak yang menonton tv tanpa berdialog dengan orangtua. Sementara itu belum ada penelitian yang meneliti tentang pengaruh intensitas menonton film anak di youtube. Sehubungan dengan itu, peneliti ingin mengetahui intensitas pengaruh menonton film di youtube terhadap ToM pada anak usia 4-5 tahun. Selain itu penelitian ini juga bertujuan untuk mengetahui gambaran perkembangan ToM anak prasekolah dan intensitas menonton film anak-anak di youtube.

\section{METODE}

Partisipan dalam penelitian ini adalah anak yang berusia 4-5 tahun (prasekolah). Menurut para ahli, kemampuan anak memahami mental state orang lain mulai berkembang dengan pesat pada usia 3-5 tahun (Shahaeian, Peterson, Slaughter \& Wellman, 2011). Peneliti juga menentukan kriteria partisipan bersekolah di Taman Kanak-Kanak (TK). Prosedur ini dilakukan untuk mendapatkan kriteria yang sama seperti fasilitas belajar yang sama. Selain itu, tujuannya untuk memudahkan peneliti memperoleh informasi tentang perkembangan anak misalnya informasi mengenai kemampuan verbal anak. Karakteristik orangtua ditentukan berdasarkan pendapatan berkisar Rp 5.000.000,. - Rp 10.000.000,. per bulan dan pendidikan minimal SMA. Prosedur ini dilakukan berdasarkan pendapatan dari Pears dan Moses (2003) yang menyatakan bahwa status sosial ekonomi, demografi dan pendidikan orangtua memiliki hubungan dengan perolehan ToM. Penelitian dilakukan di 5 kota di Pulau Sumatera yaitu Pariaman, Agam, Bukittinggi, Sibolga dan Jambi

Pengukuran ToM menggunakan skala ToM yang dikembangkan oleh Wellman dan Liu yang telah diadaptasi dalam bahasa dan budaya Indonesia oleh Kuntoro, Saraswati, Peterson dan Slaughter (2013), Rusli, Kuntoro, Handayani, Nurmina dan Arben (2020), Rusli dan Nurmina (2020). Skala ToM terdiri dari lima penugasan yang diberikan dalam bentuk cerita untuk melihat pemahaman anak terhadap konsep diverse desire (DD), diverse belief (DB), knowledge access (KA), false belief (FB) dan hidden emotion (HE).

Kelima tugas dari skala ToM terdiri dari pertanyaan kontrol dan pertanyaan target. Pertanyaan kontrol bertujuan untuk mengetahui sejauh mana pemahaman anak tentang alur cerita sedangkan pertanyaan target bertujuan untuk mengukur pemahaman anak terhadap setiap konsep ToM. Pemahaman ToM dapat diketahui dari ketepatan respon anak dalam menjawab pertanyaan target dan pertanyaan kontrol. Contohnya dalam penugasan DD, eksperimenter memberikan showcard yang bergambar 2 makanan. Partisipan diminta untuk memilih makanan mana yang mereka sukai. Setelah anak memberikan jawaban pilihan, anak diberikan informasi pilihan makanan yang disukai anak lain (diwakili karakter anak perempuan dalam bentuk boneka) yang bertentangan dengan pilihan anak. Selanjutnya anak diminta untuk memberikan prediksi anak lain terhadap makanan tersebut berdasarkan kesukaan anak lain (boneka). Pertanyaan kontrol: " mana makanan yang paling kamu suka?". Pertanyaan Target : "apa yang ingin dia (boneka) makan?" Kelima penugasan ToM diberikan secara bertahap mulai dari $\mathrm{DD}>\mathrm{DB}>\mathrm{KA}>\mathrm{FB}>$. Pengulangan penyampaian cerita bisa 
dilakukan sebanyak dua kali jika anak belum bisa menjawab pertanyaan kontrol. Sementara itu, untuk pertanyaan target tidak dilakukan pengulangan jika anak belum bisa menjawab dengan benar pertanyaan tersebut. Anak diberikan reward biskuit wafer setelah ia menyelesaikan eksperimen ToM. Pelaksanaan eksperimen ToM memerlukan waktu maksimal 10 menit setiap anak. Skala ToM memiliki koefisien reliabilitas dengan nilai reprodusibilitas sebesar 0.929 .

Keterpaparan anak pada film di youtube diperoleh dengan menyebarkan kuesioner pada orangtua partisipan anak selesai anak mengerjakan tes ToM. Kuesioner dibuat dalam 2 versi yaitu manual dan google form. Pertanyaan dalam kuesioner meliputi jumlah judul film anak-anak di youtube yang ditonton anak, berapa kali (frekuensi) anak menonton film dalam 1 minggu, dan berapa lama (durasi) anak menonton film dalam 1 hari. Sebelum disebar, kuesioner di tes baca kepada 3 orangtua untuk mengetahui apakah pertanyaan kuesioner dapat dipahami/tidak. Orangtua yang telah mengisi kuesioner mendapat kenang-kenangan berupa tasbih/bros. Sehubungan dengan masa pandemi covid 19 kegiatan belajar mengajar di sekolah ditiadakan. Peneliti melalui pihak sekolah meminta terlebih dahulu kesediaan orangtua murid terlibat dalam peneliian dengan menandatangani informed consent. Eksperimen ToM sebagian dilakukan disekolah dengan meminta orangtua membawa anak-anak mereka kesekolah secara bergantian, sebagian dilakukan di rumah partisipan. Penelitian ini menggunakan analisis regresi sederhana untuk mengetahui pengaruh menonton film youtube terhadap ToM anak.

\section{HASIL}

Gambaran perkembangan ToM anak prasekolah dalam penelitian ini dapat dilihat pada Tabel 1. Berdasarkan tabel 1. dapat diketahui bahwa skor konsep ToM tertinggi adalah diverse desire (98.6\%), dan konsep ToM terendah adalah hidden emotion (44.2\%). Dengan demikian urutan perkembangan ToM anak usia 4-5 tahun adalah sebagai berikut $\mathrm{DD}>\mathrm{DB}>\mathrm{KA}>\mathrm{FB}>\mathrm{HE}$.

Tabel 1.

ToM Usia 4-5 Tahun

\begin{tabular}{lc}
\hline \multicolumn{1}{c}{ Konsep ToM } & $\begin{array}{l}\text { Jumlah dan Prosentase } \\
\text { Jawaban Benar }(\%)\end{array}$ \\
\hline Diverse Desires (DD) & $212(98.6 \%)$ \\
\hline Deserve Belief (DB) & $208(96.7 \%)$ \\
\hline Knowledge Access (KA) & $186(86.5 \%)$ \\
\hline False Belief (FB) & $134(62.3 \%)$ \\
\hline Hidden Emotion (HE) & $95(44.2 \%)$ \\
\hline
\end{tabular}

Sementara itu gambaran tentang intensitas menonton film di youtube dapat dilihat pada Tabel 2. Pada tabel 2 dapat dilihat bahwa anak menonton film di youtube paling lama kurang atau sama dengan 7 jam perminggu, artinya anak-anak menonton youtube setiap hari minimal 1 jam sehari. Sementara hanya 5 anak yang tidak mengakses film melalui youtube. 
Tabel 2.

Intensitas Menonton Film Youtube

\begin{tabular}{cc}
\hline Durasi Menonton Film Youtube & Jumlah Anak \\
\hline Tidak pernah & $5(2,33 \%)$ \\
$\leq 7 \mathrm{jam} / \mathrm{mg}$ & $89(41.34 \%)$ \\
$8-14 \mathrm{jam} / \mathrm{mg}$ & $82(38.14 \%)$ \\
$15-28 \mathrm{jam} / \mathrm{mg}$ & $30(13.95 \%)$ \\
$\geq 35 \mathrm{jam} / \mathrm{mg}$ & $9(4.19 \%)$ \\
\hline Total & 215 \\
\hline
\end{tabular}

Peneliti menguji pengaruh intensitas menonton film anak-anak di youtube terhadap ToM anak usia 4-5 tahun dengan menggunakan simple regression dengan program SPSS. Berdasarkan hasil analisis data diketahui bahwa intensitas menonton film youtube tidak berpengaruh secara signifikan terhadap ToM dengan $\mathrm{R}=0.019$ dan $\mathrm{R}^{2}=.000, p>0.05$. Selanjutnya hasil analisa uji intensitas menonton film youtube terhadap ToM anak dapat diketahui melalui tabel berikut ini:

Tabel 3.

Analisis Regresi Pengaruh Intensitas Menonton Film di youtube terhadap ToM

\begin{tabular}{lclccl}
\hline \multicolumn{1}{c}{ Variabel } & $B$ & $S E B$ & $\beta$ & $t$ & $p$ \\
\hline $\begin{array}{l}\text { Intensitas Menonton film } \\
\text { di youtube }\end{array}$ & -0.020 & 0.72 & -0.019 & -.274 & .784 \\
\hline $\mathrm{R}^{2}=.000 \mathrm{~N}=215, p>0.05$ & & & & & \\
\hline
\end{tabular}

Berdasarkan Tabel 1 diketahui bahwa intensitas menonton film anak di youtube memiliki koefisien regresi yang tidak signifikan $(\beta=-0.019, \mathrm{p}>0.05)$. Dengan demikian Ha ditolak, artinya intensitas menonton film di youtube tidak berpengaruh secara signifikan terhadap ToM anak-anak usia 4-5 tahun.

\section{DISKUSI}

Penelitian ini menjawab pertanyaan penelitian apakah intensitas menonton film anak di youtube berpengaruh terhadap ToM pada anak usia 4-5 tahun. Berdasarkan hasil analisis regresi sederhana diperoleh kesimpulan bahwa intensitas menonton film di youtube tidak signifikan mempengaruhi ToM pada anak usia 4-5 tahun. Hasil penelitian ini menunjukkan bahwa intensitas menonton film anak di youtube bukan salah satu faktor yang mempengaruhi ToM anak-anak prasekolah.

Hasil penelitian ini hampir sama dengan penelitian sebelumnya yang menemukan bahwa ketertaparan pada acara TV diantaranya film anak-anak tidak signifikan mempengaruhi ToM (Mar, dkk, 2010). Mereka berasumsi hal tersebut disebabkan oleh jeda iklan di acara TV yang dapat mengganggu perhatian anak pada cerita yang tayang di TV. Hasil penelitian Rusli, Ariani, Nurmina, dan Rinaldi (2021) juga menemukan hal yang sama yaitu paparan film anak-anak di TV tidak berpengaruh terhadap kemampuan ToM anak prasekolah. Mereka menduga hal yang sama dengan Mar, dkk (2021) bahwa penayangan film di TV yang dijeda iklan-iklan komersial menjadi salah satu penyebab paparan film anak tidak mendukung perkembangan ToM anak prasekolah. Dalam penelitian ini, peneliti menduga hal yang sama dengan asumsi para peneliti sebelumnya. Meskipun kehadiran iklan komersial acara di TV tidak sebanyak di Youtube namun beberapa film anak di Youtube masih diselingi dengan iklan, sehingga diperkirakan dapat mempengaruhi kemampuan anak memahami cerita. Menurut Shrum (2004) jika perhatian anak selama menonton berkurang, maka informasi dari tontonan akan semakin sulit diserap 
oleh anak. Artinya, jeda iklan dapat menghambat kemampuan anak memahami keadaan mental yang disuguhkan melalui cerita film di youtube, sehingga intensitas menonton film di Youtube tidak memengaruhi ToM anak..

Faktor lain yang kemungkinan dapat mempengaruhinya adalah diduga film-film yang ditayangkan di youtube merupakan film impor yang masih menggunakan bahasa asing seperti bahasa Inggris sehingga menyulitkan anak memahami cerita film. Selain itu, partisipan anak banyak yag belum bisa dengan lancar membaca subtitle dalam bahasa Indonesia. Kemungkinan lainnya, terdapat film-film youtube naratif yang ditonton oleh anak-anak misalnys film animasi angry bird/owl dan lain-lain. Sebagaimana dikatakan oleh para peneliti bahwa media naratif (film) dapat menunjang perolehan ToM jika cerita yang terdapat didalamnya menggambarkan konteks sosial dan mengandung banyak kalimat yang menjelaskan mengenai keadaan mental (Dyer, Shatz, \& Wellman, 2000; Mar, dkk, 2010).

Selain itu, diduga ketiadaan pendampingan orangtua saat anak menonton film di Youtube kemungkinan dapat menjadi penyebab paparan film di youtube tidak berpengaruh terhadap pemahaman mental state orang lain. Berdasarkan hasil penelitian Nathanson, dkk (2013) menemukan bahwa acara-acara di televisi (salah satunya film) dapat mendukung performa ToM bagi anak-anak yang didampingi oleh orangtua saat menonton acara di TV. Mereka mengatakan bahwa cerita dari acara yang ditayangkan di TV menjadi materi atau topik yang menghantarkan anak membicarakan tentang mental state dengan orangtuanya.

Hasil penelitian ini juga menunjukkan bahwa terdapat faktor lain yang lebih berperan dalam mengembangkan perolehan theory of mind anak, seperti percakapan antara ibu dan anak (Ruffman, Slade, \& Crowe, 2002), diskusi antara anak dengan orangtua tentang acara televisi (Nathanson, dkk, 2013) dan pengasuhan orangtua (Vinden, 2001).

Temuan penelitian ini juga memperoleh informasi tentang perkembangan ToM anak prasekolah di Indonesia, khususnya di pulau Sumatera. Urutan perkembangannya mengikuti anak-anak prasekolah di negara-negara barat, hal ini menunjukkan bahwa ToM berkembang universal meskipun di konteks budaya yang berbeda (Kuntoro, dkk, 2013; Rusli, dkk, 2020)

Keterbatasan penelitian ini adalah penelitian tidak melihat seberapa banyak informasi tentang situasi mental yang terkandung dalam film anak yang ditayangkan di TV. Hal ini menjadi dugaan peneliti mengapa intensitas menonton film di youtube tidak mempengaruhi ToM. Penelitian ini juga tidak menggali pemahaman anak tentang interaksi sosial dari cerita dalam film yang mereka tonton. Selain itu, penelitian ini juga tidak melihat interaksi anak dan orangtua saat menonton film di youtube.

Berdasarkan paparan kesimpulan dan diskusi yang telah dijabarkan di atas, peneliti menyarankan untuk penelitian selanjutnya terkait dengan hubungan intensitas menonton film anak di youtube dan ToM, yakni peneliti selanjutnya diharapkan dapat menggali informasi tentang film-film yang bercerita tentang situasi mental. Penelitian selanjutnya juga perlu melihat interaksi antara orangtua dan anak selama menonton youtube yang dapat berperan dalam perkembangan ToM.

\section{KESIMPULAN}

Hasil penelitian menunjukkan tidak terdapat pengaruh yang signifikan intensitas menonton film anak di Youtube terhadap ToM pada anak usia 4-5 tahun. Berbagai kemungkinan dapat menjadi alasan mengapa tidak ditemukan pengaruhnya antara lain, diprediksikan karena jeda iklan komersial di tayangan film. Selain itu diduga film-film di youtube masih banyak menggunakan bahasa asing dan subtitle sehingga anak yang belum bisa membaca sulit memahami cerita dari film serta menyulitkan anak menghubungkan dengan situasi mental yang ditemukannya dalam kehidupan sehari-hari. Kedepannya riset ini masih perlu dikembangkan 
untuk melihat pengaruh media naratif lainnya yang mempengaruhi perolehan ToM anak seperti buku cerita dan sebagainya.

\section{DAFTAR PUSTAKA}

Caputi, M., Lecce, S., Pagnin, A., \& Banerjee, R. (2012). Longitudinal effects of theory Of mind on later peer relations: the role of prosocial behavior. Developmental Psychology, 48, 257-270.

Dyer, J. R., Shatz, M., \& Wellman, H. M. (2000). Young children's storybooks as a source of mental state information. Cognitive Development, 15, 17-37.

Foote, R. C., \& Holmes-Lonergan, H. A. (2003). Sibling conflict and theory of mind. British Journal of Developmental Psychology, 21(1), 4558.https://doi.org/10.1348/026151003321164618

Guajardo, N. R., \& Watson, A. C. (2002). Narrative discourse and theory of mind development. The Journal of Genetic Psychology, 163, 305-325.

Kinnebrock, S., \& Bilandzic, H. (2006, Juni). "How to make a story: Introducing the concept of narrativity into narrative persuasion." Paper presented at the International Communication Association Conference, Dresden. Retrieved January, 23, 2014 from http://darwin.bth.rwth-aachen.de/opus3/volltexte/2011/3638/pdf/3638.pdf

Kuntoro, I. A., Saraswati, L., Peterson, C., \& Slaughter, V. (2013). Micro-cultural influences on theory of mind development: A comparative study of middle-class and pemulung children in Jakarta, Indonesia. International Journal of Behavioral Development, 37(3), 266-273. https://doi.org/10.1177/0165025413478258

Lalonde, C., \& Chandler, M. (1995). False belief understanding goes to school On the socialemotional consequences of coming early or late to a first theory of mind. Cognition and Emotion, 9.

Mar, R. A., Tacket, J. L., \& Moore, C. (2010). Exposure to media and theory-of-mind development in preschoolers. Cognitive Development, 25, 69-78.

Moen, K. (2013). Film and fairy tales: The birth of modern fantasy. London: I.B. Tauris.

Nathanson, A. L., Sharp, M. L., Alade, F., Rasmussen, E. E., \& Christy, K. (2013). The relation between television exposure and theory of mind among preschoolers. Journal of Comunication, 63(6), 1088-1108.

Pears, K. J., \& Moses, L. J. (2003). Demographics, Parenting and Theory of Mind in Preschool Children. Social Development (pp. 12; 1-20). Oxford UK: Blackwell Publishing. Ratner, N. K., \& Olver, R. R (1998). Reading a tale of deception, learning a theory of mind? Early Childhood Research Quarterly, 13, 219-239.

Richner, E. S., \&Nicolopoulou, A. (2001). The narrative construction of differing conceptions of the person in the development of young children's social understanding. Early Education \& Development, 12.393-432.

Ruffman, T., Slade, L. \& Crowe, E. (2002). The relation between children's and mothers'mental state language and theory-of-mind understanding. Child Development, 73,734-751.

Rusli, D., Kuntoro, I. A., Handayani, E., Nurmina, \& Arben, A. (2020). The influence of individualism and collectivism parenting on theory-of-mind acquisition in children aged 3-5. International Journal of Psychosocial Rehabilitation,24(9), 30533063. https://doi.org/10.37200/IJPR/V24I9/PR290333

Rusli, D. \& Nurmina. (2020). Pengaruh Gaya Pengasuhan Autonomy dan Conformity Terhadap Perolehan Theory-of-Mind pada Anak Prasekolah di Sumatera Barat. Jurnal RAP (Riset Aktual Psikologi) Universitas Negeri Padang, 113-127.

Rusli, D., Ariani, D. N., Nurmina, N., \& Rinaldi, R. (2021). Influence of exposure to children's 
movies on television on theory-of-mind acquisition in preschoolers. International Journal of Health \& Medical Sciences, 4(1), 44-49. https://doi.org/10.31295/ijhms.v4n1.650

Scholl, B. J., \& Leslie, A. M. (2001). Minds, modules, and meta-analysis. Commentary on "Meta-analysis of theory-of-mind development: The truth about false belief." Child Development, 72(3), 696-701. https://doi.org/10.1111/1467-8624.00308

Shrum, L., J. (2004). The cognitive processes underlying cultivation effects are a function of whether the judgmentsare on-line or memory-based. Communications, 29, 327-344.

Shahaeian, A., Peterson, C.C, Slaughter, V., \& Wellman, A. M, (2011). Culture and the sequence of step in theory of mind development. Development Psychological. Vol 47, 5, 1239-1247.

Slaughter, V., Dennis, M., \& Pritchard. M. (2002). Theory of mind and peer acceptance in preschool children. British Journal of Developmental Psychology, 20

Van Mierlo, J. (2008, May). "How to measure television exposure from a contents-received point of view?"Paper presented at the annual meeting of the Internasional Communication Association, TBA, Montreal, Quebec, Canada. Retrieved January, 1, 2014fromhttps://doclib.uhasselt.be/dspace/bitstream/1942/8337/1/paperICA2008bloot stelling.pdf

Vinden, P. G. (2001). Parenting attitudes and children's understanding of mind a comparison of Korean American and Anglo American families. Cognitive Development. Volume $16: 793-809$.

Wellman, H. M., Liu, D. (2004). Scalling theory of mind tasks. Child Development

Wellman, H. M., Cross, D., \& Watson, J. (2001). Meta analysis of theory of mind development: the truth about false belief. Child Development, vol. 72, 3, 655-684

Wimmer, H., \& Perner, J. (1983). Beliefs about beliefs: Representation and constraining function of wrong beliefs in young children's understanding of deception. Cognition, Vol. 13, 103-128.

www.kpai.go.id. (2020, 10 Februari). Sejumlah Kasus Bullying Sudah Warnai Catatan Masalah Anak di Awal 2020. Diakses pada 10 Februari 2020, dari https://www.kpai.go.id/berita/sejumlah-kasus-bullying-sudah-warnai-catatan-masalahanak-di-awal-2020-begini-kata-komisioner-kpai. 